\title{
EXHIBITION
}

\section{Alluring Objects}

\section{Cornelia Parker}

Mary Griffiths, Curator

The Whitworth, Manchester

14 February 2015 to 31 May 2015 ized, habit.

The performance that opened the exhibition was a collaboration between Parker and Sir Konstantin Novoselov, who won the Nobel Prize for Physics in 2010 for his co-discovery of graphene. For the piece, Novoselov extracted graphite crystals from pencil traces on a drawing by the Romantic painter and poet William Blake and used these to produce a sample of graphene. The graphene was used to create a field effect transistor that formed the basis of a humidity-sensitive sensor. When Novoselov breathed on the sensor (Breath of a Physicist, 2015), a firework display, choreographed by Parker, was initiated (Blakean Abstract, 2015). The emphasis here is on a constant material transformation that defies our efforts to fix the nature and meaning of objects. What such a bravura spectacle also celebrates, of course, is the potential not only for a meeting of minds between artists and scientists, but of a more visceral mingling of bodies at work.

\subsection{6/science. aab0533 goes here}

Legend goes here has been taken a step further in subsequen pieces. Some of these are playful: for example, Measuring Niagara with a Teaspoon (2007) stretches this dainty object into a wire the height of Niagara Falls, while Composition with Horns (Double Flat) (2005) consists of sixteen instruments crushed by an industrial press and suspended inches above the floor. However, there is no doubting Parker's preoccupation with objects that highlight the linkages between the state and violence and suffering. A filmed interview with Noam Chomsky (2007) on the banalization of violence and cruelty, for example, is followed up by a series of needlework samplers (2015) produced by inmates of Her Majesty's Prisons, each of which are inscribed with dictionary definitions of war and peace, life and death, light and dark and so on. A specially commissioned installation, War Room (2015), uses the perforated reams of red paper from which war memorial poppies are cut to swathe an entire gallery wing. There is no sentimentality here, but rather a reference to the manner in which remembrance has itself become an unreflective, readily industrial-

The reviewer is at the School of Geographical and Earth Sciences, University of Glasgow, East Quadrangle, University Avenue, Glasgow G12 8QQ, Scotland. E-mail: deborah.dixon@glasgow.ac.uk 